\title{
Tension pneumothorax in a patient with COVID-19
}

\author{
Luke Flower 다 , ${ }^{1}$ John-Paul L Carter, ${ }^{2}$ Juan Rosales Lopez, ${ }^{2}$ Alun Marc Henry ${ }^{2}$
}

${ }^{1}$ Anaesthesia, University College London Hospitals NHS Foundation Trust, London, UK 2Emergency Department, University College London Hospitals NHS Foundation Trust, London, UK

\section{Correspondence to Dr Luke Flower: luke.flower@doctors.org.uk}

Accepted 7 May 2020

Check for updates

(C) BMJ Publishing Group Limited 2020. No commercial re-use. See rights and permissions. Published by BMJ.

To cite: Flower L, Carter J-PL, Rosales Lopez J, et al. BMJ Case Rep 2020:13:e235861. doi:10.1136/bcr-2020 235861

\section{SUMMARY}

A 36-year-old man was brought to the emergency department with suspected COVID-19, following a 3week history of cough, fevers and shortness of breath, worsening suddenly in the preceding 4 hours. On presentation he was hypoxaemic, with an $\mathrm{SpO}_{2}$ of $88 \%$ on $15 \mathrm{~L} / \mathrm{min}$ oxygen, tachycardic and had no audible breath sounds on auscultation of the left hemithorax. Local guidelines recommended that the patient should be initiated on continuous positive airway pressure while investigations were awaited, however given the examination findings an emergency portable chest radiograph was performed. The chest radiograph demonstrated a left-sided tension pneumothorax. This was treated with emergency needle decompression, with good effect, followed by chest drain insertion. A repeat chest radiograph demonstrated lung re-expansion, and the patient was admitted to a COVID-19 specific ward for further observation. This case demonstrates tension pneumothorax as a possible complication of suspected COVID-19 and emphasises the importance of thorough history-taking and clinical examination.

\section{BACKGROUND}

Amidst the current COVID-19 pandemic clinicians are seeing a dramatic change in the way emergency medical services are having to function. With severe acute respiratory syndrome coronavirus 2 (SARS-CoV2) infection placing a substantial burden on healthcare services worldwide and accounting for a large proportion of emergency presentations, it is tempting to use standardised protocols to efficiently manage growing numbers of similar cases/ presentations.

While guidelines and standard operating procedures are important clinical tools, they provide no substitution for good history-taking and clinical examination. In this case, we describe a patient with suspected underlying COVID-19 presenting with a tension pneumothorax. While continuous positive airway pressure (CPAP) would have been indicated given the clinical picture and onset of the patient's symptoms, applying such protocol-driven treatment in the context of a tension pneumothorax would likely have resulted in further deterioration and even iatrogenic cardiac arrest.

Thus, despite the current prevalence of COVID-19 associated type-1 respiratory failure, it is essential that we maintain an open mind and consider a broad set of differential diagnoses when presented with rapidly decompensating COVID-19 infection.

\section{CASE PRESENTATION}

A 36-year-old man was brought to the emergency department via blue-light ambulance with suspected SARS-CoV2 infection, presenting with a 3-week history of a dry cough, fevers and shortness of breath. He reported significantly worsening breathlessness in the previous 4 hours with associated left-sided pleuritic chest pain. His medical history was significant only for childhood asthma, and a 10 pack-year history of smoking. He had no history of recent trauma or previous pneumothoraces. The patient worked as a courier and had previously held roles in domestic cleaning.

The patient was seen in a resuscitation cubicle with attending staff in full personal protective equipment. On presentation, the patient was significantly hypoxaemic, with an $\mathrm{SpO}_{2}$ of $88 \%-90 \%$ on $15 \mathrm{~L} / \mathrm{min}$ of oxygen via non-rebreathe mask, a respiratory rate of 50 breaths per minute, using accessory muscles of respiration and tachycardic with a regular heart rate of 150 beats $/ \mathrm{min}$. His trachea remained central, with a jugular venous pressure $3 \mathrm{~cm}$ above the sternal angle and a blood pressure of $110 / 65 \mathrm{~mm} \mathrm{Hg}$.

On auscultation, breath sounds were absent throughout the left hemithorax with associated reduced vocal fremitus and asymmetrical chest expansion.

\section{INVESTIGATIONS}

A portable anteroposterior chest radiograph was performed demonstrating a large left-sided pneumothorax with mediastinal shift and radiological signs of tension (figure 1). The right lung while compressed displayed signs of severe COVID-19, that is, widespread patchy consolidative changes.

The patient's full blood count demonstrated a raised white cell count $\left(13.64 \times 10^{9} / \mathrm{L}\right)$ with a neutrophilia $\left(8.91 \times 10^{9} / \mathrm{L}\right)$, lymphocyte count $\left(3.81 \times 10^{9} / \mathrm{L}\right)$, haemoglobin $(146 \mathrm{~g} / \mathrm{L})$, and platelets $\left(1051 \times 10^{9} / \mathrm{L}\right)$; biochemical markers demonstrated a raised C-reactive protein $(28.7 \mathrm{mg} / \mathrm{L})$ and alanine aminotransferase (107 IU/L). These findings supported the possibility of superimposed bacterial infection on a background of COVID-19. A 12-lead ECG showed a sinus tachycardia at 155 beats/min.

Lung ultrasound following definitive treatment demonstrated multiple confluence B-lines with pleural thickening bilaterally, in keeping with a diagnosis of COVID-19 (figure 2). ${ }^{12}$ A repeat chest radiograph was also performed, confirming lung re-expansion with extensive bilateral consolidation (figure 3).

The patient underwent thoracic CT the following day which demonstrated widespread areas of patchy 


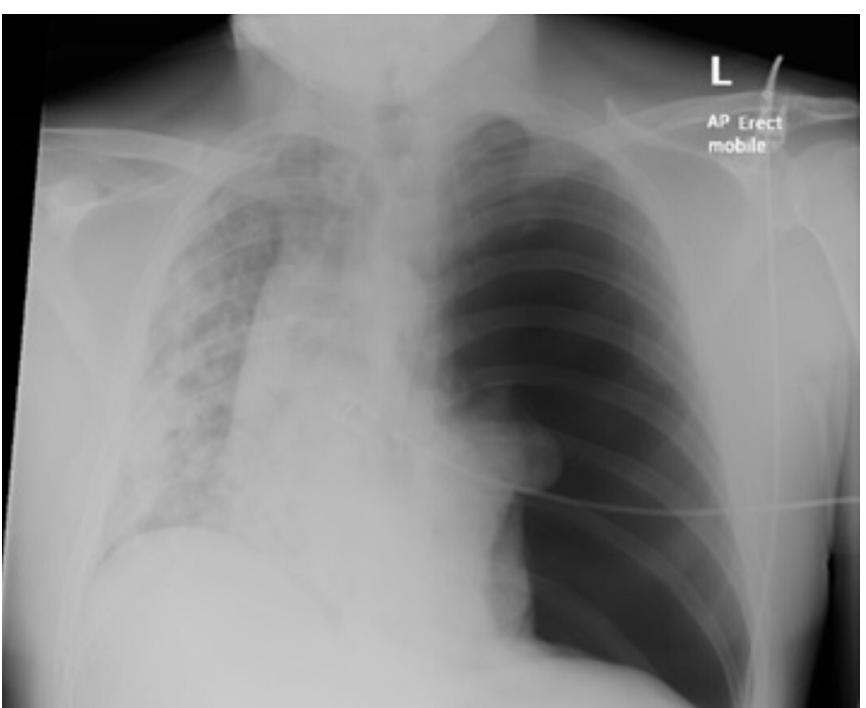

Figure 1 Portable chest radiograph demonstrating a left-sided tension pneumothorax, with mediastinal shift and consolidation throughout the right lung.

consolidation, findings consistent with severe COVID-19 infection, with associated bullae (figure 4).

\section{DIFFERENTIAL DIAGNOSIS}

Differential diagnoses for respiratory distress and type- 1 respiratory failure in the context of preceding upper respiratory tract infective symptoms may be heavily influenced by the COVID-19 pandemic, with patients presenting in respiratory failure presumed to have COVID-19 until proven otherwise. While the acute deterioration of this patient's condition could still be a result of isolated SARS-CoV2 infection, the rapid decompensation and unilateral examination findings here point away from this as the primary cause. In view of the history, examination and radiological findings, it is highly likely this patient had been suffering from COVID-19, which was then complicated by a pneumothorax.

A tension pneumothorax, possibly secondary to underlying COVID-19, was diagnosed. The prolonged onset of symptoms could easily distract one from this initially, and thus it highlights

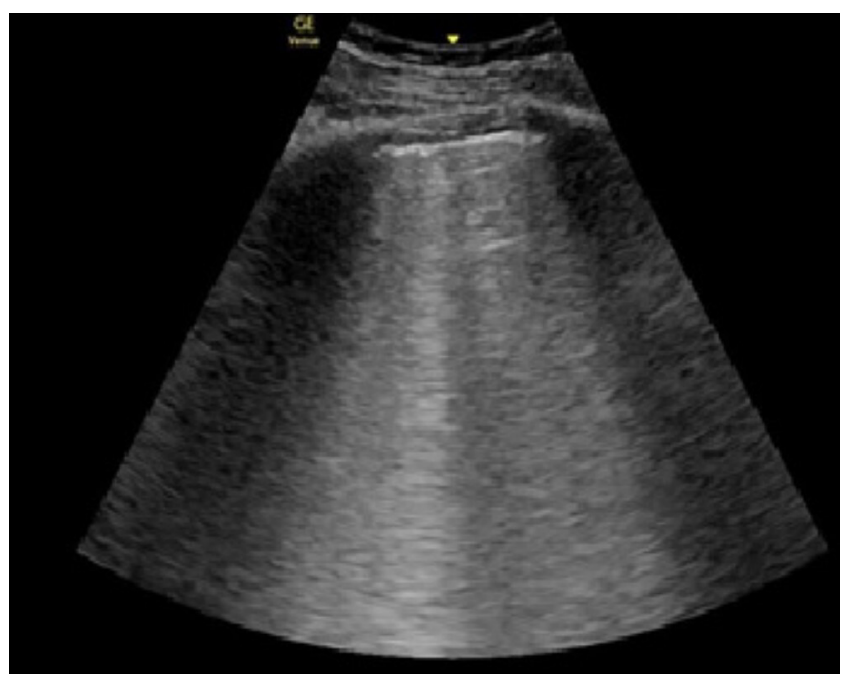

Figure 2 Point of care lung ultrasound demonstrating confluent Blines, a finding commonly reported in COVID-19.

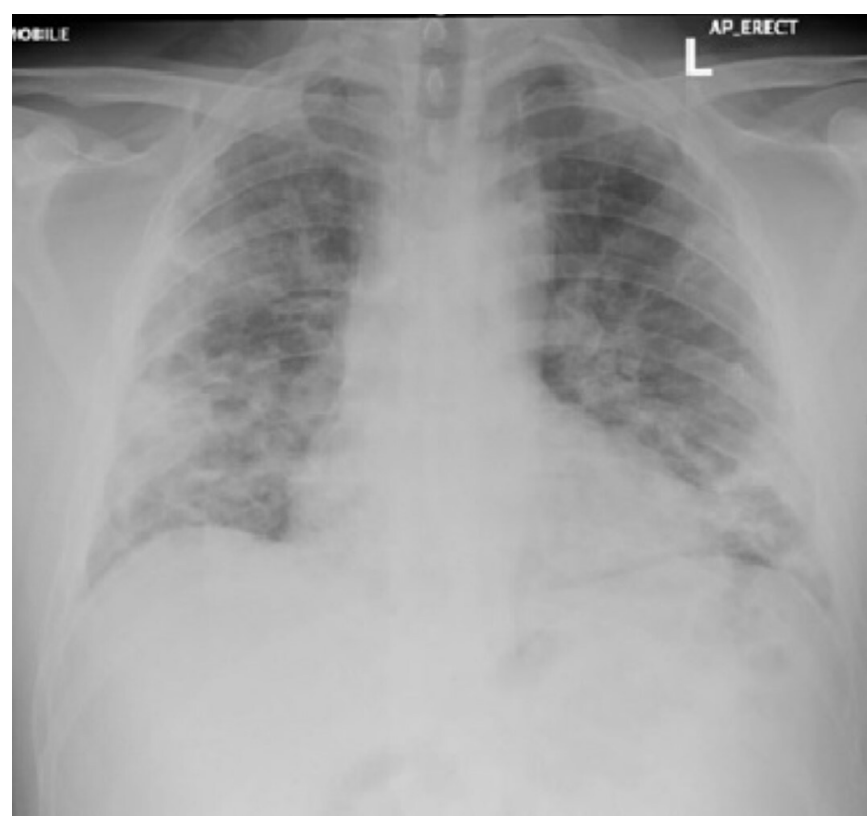

Figure 3 Portable chest radiograph demonstrating lung re-expansion and extensive bilateral consolidation in keeping with severe COVID-19.

the importance of detailed history-taking and clinical examination to ensure the correct treatment and imaging is performed in good time.

An important further differential diagnosis in the context of similar symptoms is pulmonary embolism (PE). Patients with PE present with hypoxia, tachycardia and often are vulnerable to acute deterioration if untreated. ${ }^{3}$ The literature reflects that COVID-19 may present with haemoptysis (a symptom of acute $\mathrm{PE}$ ) and it is well-known that patients who are unwell for long periods are at a higher risk of developing venous thromboembolism. Indeed, several case reports describe PE as a complication of COVID-19 infection causing acute deterioration in patients. ${ }^{4}$

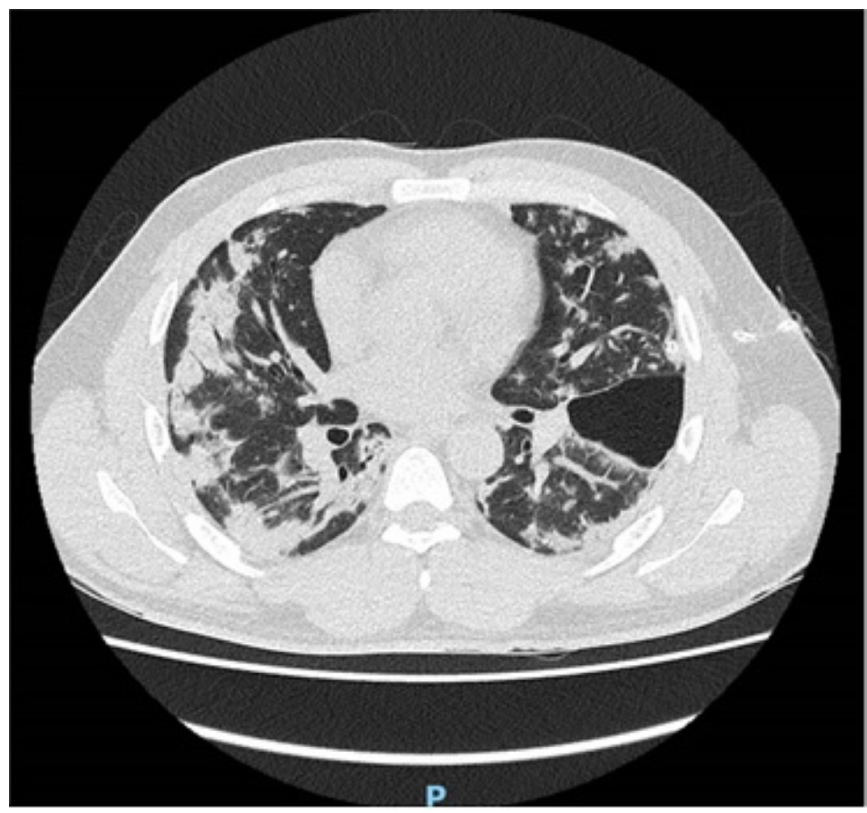

Figure 4 Thoracic CT demonstrating widespread areas of patchy consolidation, findings consistent with severe COVID-19 infection, with associated bullae. 
Patient's perspective

Initially I had 2-3 weeks of symptoms that felt like coronavirus. I had start to feel better, then on the day of admission I suddenly began to feel much more unwell and short of breath with a chest pain from the left side of my chest through to my back, more painful with every breath. After initial treatment I felt much better, but still worried about what had caused it.

I have never had anything like this before, but I think my father had a history of lung problems secondary to his smoking. I have lived in London for the past 19 years and smoked reasonably heavily for a 5 -year period when I first moved here.

I now feel much better, my pain has gone and my breathing has returned to normal. I am very keen to go home but slightly nervous about the future. (Translated from Spanish.)

\section{Learning points}

- Despite the current COVID-19 pandemic it is vital we maintain an open diagnostic mind when approaching critically unwell patients.

- In patients with suspected COVID-19, pneumothorax should be considered as a cause of acute decompensation.

- While protocols play an important role in the management of acutely unwell patients, they do not replace thorough historytaking and clinical examination.

- If two feasible diagnoses have opposing management strategies, rapid and effective diagnostic techniques, such as point of care ultrasound, should be called on.

\section{TREATMENT}

On review of the chest X-ray, the patient was treated with immediate emergency needle decompression of his pneumothorax with a 14-gauge cannula inserted in the second rib space and mid-clavicular line.

Following initial decompression, a 12-French Seldinger chest drain was inserted into the patients left axilla.

\section{OUTCOME AND FOLLOW-UP}

The treatment resulted in immediate improvement in respiratory and cardiovascular physiology with clinical and radiological evidence of lung re-expansion (figure 3). Within an hour the patient's oxygen requirement reduced from $15 \mathrm{~L} / \mathrm{min}$ via a nonrebreathe mask, to $4 \mathrm{~L} / \mathrm{min}$ via nasal cannula, with normalisation of respiratory and heart rate.

The patient was admitted to a COVID-19 ward, with full lung re-expansion and successful chest drain removal performed 2 days later. His initial COVID-19 swab returned negative, however after review of the history and imaging by the infectious diseases team it was felt he very likely had COVID-19, and it was the delay in his presentation that resulted in a negative swab result. He was discharged 2 days after this, and awaits outpatient follow-up with the respiratory team.

\section{DISCUSSION}

This case introduces the consideration of tension pneumothorax as a cause of acute deterioration in patients with underlying SARS-CoV2 infection. The importance of correctly diagnosing secondary lung pathology consequential to COVID-19 lies in the contrasting treatment strategies required for the two, with potentially life-threatening consequences if the incorrect management route is chosen. The benefits of rapid bedside diagnostic techniques, such as point of care ultrasound, are increasingly being acknowledged in COVID-19 management and may have resulted in an expedited diagnosis of a pneumothorax here if used earlier. ${ }^{2}$

It is important to acknowledge that we cannot be certain whether this pneumothorax was secondary to COVID-19 or the co-infection was purely coincidental. This patient had no previous lung imaging meaning we were unable to assess for any pre-existing lung disease or bullae. To date, no other cases of tension pneumothorax with concomitant COVID-19 infection have been published, with one case of spontaneous pneumomediastinum reported by a team of Chinese clinicians. ${ }^{5}$ Of possible relevance, multiple cases in the literature describe the presence of pneumatocoeles in patients with COVID-19, a pathological finding which may contribute to the likelihood of developing secondary pneumothoraces. ${ }^{56}$

This case further highlights the difficulties facing emergency department clinicians amidst the current pandemic. With patients presenting with respiratory failure frequently presumed to have COVID-19 until proven otherwise, thorough examination and clinical acumen is at risk of being replaced by protocoldriven treatment strategies.

Local hospital guidelines recommend that all patients with suspected COVID-19, and an $\mathrm{SpO}_{2}$ of $<94 \%$ on high flow oxygen (ie, $60 \% \mathrm{FiO} 2$ ), should be started promptly on CPAP within $10 \mathrm{~min}$ of presentation. If we had blindly followed the local guidelines and initiated CPAP, it would likely have resulted in significant deterioration and possible cardiac arrest.

Avoidance of adopting a purely algorithmic approach to critically unwell patients is extremely important. Many clinicians are no longer regularly auscultating patients' chests due to concerns around exposure to SARS-CoV2, or in some cases due to a lack of single-use stethoscopes. This puts patients at risk of being inappropriately started on incorrect treatment pathways. Admitted COVID-19 patients who are being treated with non-invasive and invasive forms of ventilation require close monitoring as they may be at increased risk of ventilator-associated pneumothorax.

In summary, while protocols remain key in the management of critically unwell patients, they cannot replace thorough historytaking and clinical examination.

\section{Twitter Luke Flower @LukeFlower1}

Contributors LF was the lead author for this case report, leading the initial patient care and management, and leading the writing of the mansucript. AMH was the consultant in charge during the case, was actively involved in decision making and patient treatment, and contributed to the manuscript. JRL was the senior registrar on call, he was actively involved in patient treatment and contributed to the manuscript. J-PLC was one of the emergency department SHOs on call, he played a significant part in the write up of the manuscript, as well as aiding with translation and patient communication.

Funding The authors have not declared a specific grant for this research from any funding agency in the public, commercial or not-for-profit sectors.

Competing interests None declared.

Patient consent for publication Obtained.

Provenance and peer review Not commissioned; externally peer reviewed.

This article is made freely available for use in accordance with BMJ's website terms and conditions for the duration of the covid-19 pandemic or until otherwise determined by BMJ. You may use, download and print the article for any lawful, non-commercial purpose (including text and data mining) provided that all copyright notices and trade marks are retained.

\section{ORCID iD}

Luke Flower http://orcid.org/0000-0001-7204-609X 


\section{Reminder of important clinical lesson}

\section{REFERENCES}

1 Huang Y, Wang S, Liu Y, et al. A preliminary study on the ultrasonic manifestations of Peripulmonary lesions of Non-Critical novel coronavirus pneumonia (COVID-19). SSRN Electronic Journal 2020.

2 Peng Q-Y, Wang X-T, Zhang L-N, et al. Findings of lung ultrasonography of novel corona virus pneumonia during the 2019-2020 epidemic. Intensive Care Med 2020:1-2.
3 Riedel M. Acute pulmonary embolism 1: pathophysiology, clinical presentation, and diagnosis. Heart 2001;85:229-40.

4 Danzi GB, Loffi M, Galeazzi G, et al. Acute pulmonary embolism and COVID-19 pneumonia: a random association? Eur Heart J 2020:ehaa254.

5 Zhou C, Gao C, Xie Y, et al. COVID-19 with spontaneous pneumomediastinum. Lancet Infect Dis 2020:20:510.

6 Shi H, Han X, Jiang N, et al. Radiological findings from 81 patients with COVID-19 pneumonia in Wuhan, China: a descriptive study. Lancet Infect Dis 2020;20:425-34.

Copyright 2020 BMJ Publishing Group. All rights reserved. For permission to reuse any of this content visit https://www.bmj.com/company/products-services/rights-and-licensing/permissions/

BMJ Case Report Fellows may re-use this article for personal use and teaching without any further permission.

Become a Fellow of BMJ Case Reports today and you can:

- Submit as many cases as you like

- Enjoy fast sympathetic peer review and rapid publication of accepted articles

- Access all the published articles

Re-use any of the published material for personal use and teaching without further permission

\section{Customer Service}

If you have any further queries about your subscription, please contact our customer services team on +44 (0) 2071111105 or via email at support@bmj.com.

Visit casereports.bmj.com for more articles like this and to become a Fellow 